\title{
Liberação de cálcio, magnésio e enxofre da palha de pastagem de braquiária para a soja em sistema de integração lavoura-pecuária
}

\author{
Release of calcium, magnesium, and sulfur from palisade grass straw to a soybean crop in \\ an integrated crop-livestock system
}
Flávia Werner ${ }^{1}$, Alvadi Antonio Balbinot Junior ${ }^{2}$, André Sampaio Ferreira ${ }^{1}$, Adilson de Oliveira Junior $^{2}$, Julio Cezar Franchini ${ }^{2}$, Henrique Debiasi ${ }^{2}$, Antonio Eduardo Coelho ${ }^{3 \star}$, Marcelo Augusto de Aguiar e Silva ${ }^{1}$

${ }^{1}$ Universidade Estadual de Londrina, Londrina, PR, Brasil.

${ }^{2}$ Empresa Brasileira de Pesquisa Agropecuária, Embrapa Soja, Londrina, PR, Brasil.

${ }^{3}$ Universidade do Estado de Santa Catarina, Lages, SC, Brasil. Autor para correspondência: coelhoagro7@gmail.com

Submissão: 02/10/2020 / Aceite: 14/12/2020

\begin{abstract}
RESUMO
Os resíduos de plantas que permanecem no solo em um sistema de integração lavoura-pecuária constituem em uma importante reserva de nutrientes para a cultura em sucessão. O objetivo do trabalho foi avaliar a liberação de cálcio $(\mathrm{Ca})$, magnésio $(\mathrm{Mg})$ e enxofre $(\mathrm{S})$ de palha de pastagem de Urochloa brizantha cv. BRS Piatã, cultivada em três doses de nitrogênio $(\mathrm{N})$ e submetida a duas épocas de dessecação em relação à semeadura da soja. O experimento foi conduzido em Londrina, Paraná, entre março de 2016 e março de 2018. Foram avaliadas três doses de $\mathrm{N}$ na pastagem de $U$. brizantha cV. BRS Piatã $\left(0 ; 150\right.$ e $300 \mathrm{~kg} \mathrm{~N} \mathrm{ha}^{-1}$ ), constituindo três piquetes distintos. Em cada piquete foram avaliadas duas épocas de dessecação da pastagem (60 e 15 dias antes da semeadura da soja), com quatro repetições. Os teores de $\mathrm{Ca}$ e $\mathrm{S}$ na palha de pastagem de $U$. brizantha não variam com o tempo de decomposição, enquanto os teores de $\mathrm{Mg}$ foram reduzidos, independentemente da adubação nitrogenada e da época de dessecação. A quantidade de Ca liberada pela palha de pastagem de $U$. brizantha até o final do ciclo da soja em sucessão foi de, aproximadamente, $15 \mathrm{~kg} \mathrm{ha}^{-1}$, independentemente da adubação nitrogenada e da época de dessecação. A quantidade de Mg liberada pela $U$. brizantha até o final do ciclo da soja em sucessão variou de 10 a $15 \mathrm{~kg} \mathrm{ha}^{-1}$, com tendência de haver maior quantidade liberada na presença de adubação nitrogenada na pastagem. A quantidade de $S$ liberada pela $U$. brizantha até o final do ciclo da soja em sucessão variou de 4 a $6 \mathrm{~kg} \mathrm{ha}^{-1}$, com tendência de haver menor quantidade liberada na presença de adubação nitrogenada na pastagem, independentemente da época de dessecação.
\end{abstract}

PALAVRAS-CHAVE: adubação nitrogenada na pastagem, épocas de dessecação, resíduo vegetal, Urochloa brizantha cv. BRS Piatã.

\begin{abstract}
Plant residues that remain in the soil of an integrated crop-livestock system constitute an important reserve of nutrients for crops in succession. The objective of this study was to evaluate the release of calcium (Ca), magnesium (Mg), and sulfur (S) from the decomposition of Urochloa brizantha cv. BRS Piatã pasture grass, fertilized with three different doses of nitrogen $(\mathrm{N})$ and subjected to two different desiccation periods, prior to sowing a soybean crop. The experiment was conducted in Londrina, Paraná, between March 2016 and March 2018. Three different doses of $\mathrm{N}$ were applied to a pasture of $U$. brizantha $\mathrm{cv}$. BRS Piatã $\left(0,150\right.$ and $\left.300 \mathrm{~kg} \mathrm{~N}^{-1}\right)$, forming three distinct paddocks. In each paddock, two different periods (60 and 15 days prior to sowing soybeans) for pasture desiccation were evaluated with four replications. Polynomial regression analysis was performed for the period after desiccation. $\mathrm{Ca}$ and $\mathrm{S}$ content in the $U$. brizantha straw did not vary over the course of decomposition, while magnesium content decreased, despite nitrogen fertilization and the desiccation periods. The amount of $\mathrm{Ca}$ released from $U$. brizantha straw by the end of the successive soybean cycle was approximately $15 \mathrm{~kg} \mathrm{ha}^{-1}$, despite nitrogen fertilization and the desiccation periods. The amount of $\mathrm{Mg}$ released from $U$. brizantha straw by the end of the successive soybean cycle ranged from 10 to $15 \mathrm{~kg} \mathrm{ha}^{-1}$, while the release of greater amounts tended to correspond with the presence of nitrogen fertilization in the pasture grass. The amount of $\mathrm{S}$ released from $U$. brizantha straw by the end of the successive soybean cycle ranged from 4 to $6 \mathrm{~kg} \mathrm{ha}^{-1}$, while the release of lesser amounts tended to correspond with the presence of nitrogen fertilization in the pasture
\end{abstract}


grass, despite the desiccation periods.

KEYWORDS: nitrogen fertilization applied to pasture, desiccation periods, plant residue, Urochloa brizantha cv. BRS Piatã.

\section{INTRODUÇÃO}

O sistema de integração lavoura-pecuária (ILP) tem sido amplamente divulgado nos últimos anos porque pode possibilitar ganhos econômicos, ambientais e sociais à atividade agropecuária (KUMAR et al. 2019). No entanto, para que esses ganhos sejam atingidos, é necessário explorar, por meio do manejo, as possíveis sinergias entre a pecuária e a produção vegetal, as quais podem ser potencializadas com o uso do Sistema Plantio Direto (SPD) (BALBINOT JUNIOR et al. 2009, SANTOS et al. 2014).

No Brasil, a utilização de forrageiras tropicais integrada à produção de soja (Glycine max (L.) Merr.) difundiu-se nas regiões com clima quente (NEPOMUCENO et al. 2012). A inserção de forrageiras permite a melhoria da qualidade do solo e a produção de palha para a instalação de culturas em sucessão em SPD, além de fornecer alimento de alta qualidade aos animais (FRANCHINI et al. 2014, FRANCHINI et al. 2015). Entre as espécies forrageiras utilizadas na ILP, destacam-se as do gênero Brachiaria (Syn Urochloa), devido à alta produção de biomassa radicular e aérea, mesmo em ambientes restritivos, como, por exemplo, baixa disponibilidade de água e nutrientes. Espécies desse gênero apresentam alta capacidade de absorção de nutrientes em camadas mais profundas do solo, aumentando a ciclagem desses elementos (TORRES et al. 2008, ECHER et al. 2012).

Um dos nutrientes demandados em maiores quantidades pelas gramíneas forrageiras é o nitrogênio, participando de diversos processos metabólicos por ser um elemento estrutural, resultando em aumento da produção de massa seca dessas espécies, sendo o principal nutriente para a manutenção da sua produtividade (DUPAS et al. 2016). Ao ser aplicado, o $\mathrm{N}$ é incorporado pelas plantas e agregado às cadeias de carbono, ocasionando incremento dos componentes celulares e, permitindo maior vigor do rebrote. Os macronutrientes secundários, Cálcio (Ca), Magnésio $(\mathrm{Mg})$ e Enxofre (S), apresentam função fundamental no crescimento e desenvolvimento das gramíneas forrageiras em razão da sua participação nos diversos processos bioquímicos e celulares das plantas, sendo utilizados em menores quantidades pelas plantas do que os macronutrientes primários. No entanto, o efeito positivo da adição de $\mathrm{N}$ sobre os teores de $\mathrm{Ca}, \mathrm{Mg}$ e $S$ na biomassa das plantas forrageiras e posterior liberação para a soja em sucessão ainda não está elucidado.

O período de permanência dos restos culturais sobre o solo em SPD e a dinâmica de liberação dos nutrientes são requisitos essenciais para o sucesso de todo o sistema, visando à preservação e a cobertura do solo durante toda a safra (CALONEGO et al. 2012, SANTOS et al. 2014). O correto manejo das plantas de cobertura com produtos químicos pode proporcionar maior disponibilização dos nutrientes devido à decomposição subsequente e maior persistência de palha na superfície do solo (NASCENTE \& CRUSCIOL 2012). Desse modo, a escolha da época de dessecação antes da semeadura da soja constitui uma prática de manejo importante, pois pode influenciar na liberação de nutrientes pela palha, sendo mais proveitoso para a soja que o pico da absorção de nutrientes ocorra concomitante à máxima liberação dos nutrientes pela palha (MONQUERO et al. 2010). O uso de intervalos entre a dessecação e a semeadura da soja que sincronize a liberação de nutrientes com os momentos de maior absorção pela cultura é importante para maximizar a eficiência de uso dos nutrientes (COSTA et al. 2016).

O objetivo deste trabalho foi avaliar a liberação de $\mathrm{Ca}, \mathrm{Mg}$ e $\mathrm{S}$ de palha de pastagem de U. brizantha cv. BRS Piatã cultivada em três doses de nitrogênio e submetida a duas épocas de dessecação em relação à semeadura da soja.

\section{MATERIAL E MÉTODOS}

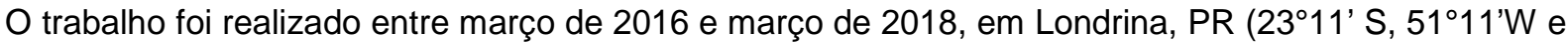
altitude de $620 \mathrm{~m}$ ). O solo foi classificado como Latossolo Vermelho distroférrico (SANTOS et al. 2018), com textura muito argilosa, que vinha sendo manejado em SPD há 15 anos, com o cultivo de soja no verão e trigo ou aveia preta no inverno.

Em março de 2016, a Urochloa brizantha cv. BRS Piatã foi implantada com linhas espaçadas em 20 $\mathrm{cm}$, em consórcio com o milho segunda safra, com $5 \mathrm{~kg}^{-1} \mathrm{ha}^{-1}$ de sementes puras e viáveis. A área experimental foi dividida em três piquetes, com aproximadamente 1,2 ha cada, sendo que cada um recebeu uma dose de $\mathrm{N}\left(0 ; 150\right.$ e $300 \mathrm{~kg} \mathrm{ha}^{-1}$ ano), na forma de ureia ( $45 \%$ de $\left.\mathrm{N}\right)$, que foram aplicados a lanço, parcelando $50 \%$ em setembro e $50 \%$ em novembro de 2016. O solo possuía os seguintes atributos na 
camada de 0 a $20 \mathrm{~cm}: 27,9 \mathrm{~g} \mathrm{dm}^{-3}$ de C orgânico; $\mathrm{pH}\left(\mathrm{CaCl}_{2}\right)$ de 4,8; $15,5 \mathrm{mg} \mathrm{dm}^{-3}$ de $\mathrm{P}\left(\mathrm{Mehlich}^{-1}\right) ; 0,53$ $\mathrm{cmol}_{\mathrm{C}} \mathrm{dm}^{-3}$ de K trocável; $3,2 \mathrm{cmol}_{\mathrm{C}} \mathrm{dm}^{-3}$ de Ca trocável; $1,4 \mathrm{cmol}_{\mathrm{c}} \mathrm{dm}^{-3}$ de Mg trocável; $15,3 \mathrm{mg} \mathrm{dm}^{-3} \mathrm{de} \mathrm{S}$ e $49 \%$ de saturação por bases.

No período de outubro de 2016 até julho de 2017 foi realizado pastejo uniforme e contínuo na área por bovinos machos com 350 a $550 \mathrm{~kg}$ de peso vivo, com lotação média de duas unidades animais (UA) $\mathrm{ha}^{-1}$, mantendo a mesma altura de pastejo $(30 \mathrm{~cm})$. Após esse período, a área foi mantida sem animais até agosto do mesmo ano, quando, em cada piquete, foram avaliadas duas épocas de dessecação: 60 e 15 dias antes da semeadura da soja (DAS), com quatro repetições. A dessecação da pastagem foi realizada com glifosato, na dose de $1.500 \mathrm{~g}$ e.a. ha ${ }^{-1}$, aplicado com pulverizador tratorizado, equipado com pontas de pulverização tipo leque, com volume de calda de $200 \mathrm{~L} \mathrm{ha}^{-1}$. As condições atmosféricas e de umidade no solo foram adequadas ao funcionamento do herbicida para as duas épocas de dessecação. Os dados meteorológicos (Figura 1) foram obtidos na estação agrometeorológica da Embrapa Soja que está distante $700 \mathrm{~m}$ da área experimental.
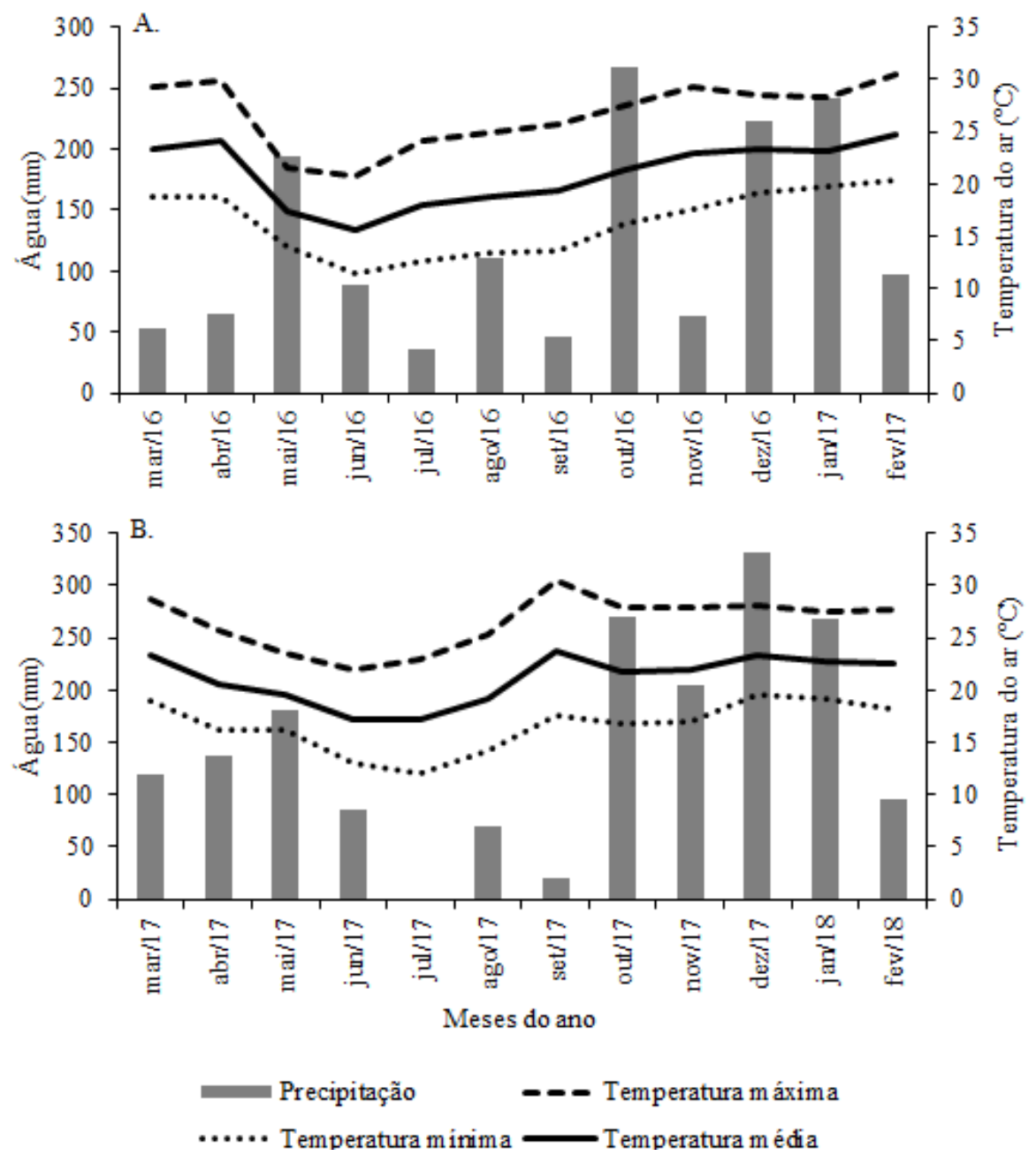

Figura 1. Precipitação pluvial acumulada $(\mathrm{mm})$ e temperaturas máximas, médias e mínimas $\left({ }^{\circ} \mathrm{C}\right)$ durante a condução da pesquisa em 2016 (A) e 2017 (B). Londrina, PR.

Figure 1. Rainfall accumulation $(\mathrm{mm})$ and maximum, mean, and minimum temperatures $\left({ }^{\circ} \mathrm{C}\right)$ during the research period in 2016 (A) and 2017 (B). Londrina, $P R$.

Para a dessecação aos 60 DAS foram realizadas sete coletas de palha $\left(1 \mathrm{~m}^{2}\right.$ por parcela) aos 13,41 , $68,90,111,139$ e 177 dias após dessecação (DAD). Na dessecação aos 15 DAS foram efetuadas seis coletas de palha aos $0,21,43,64,91$ e 129 DAD. As coletas foram realizadas manualmente, utilizando-se facas, em que toda palha superficial contida em $1 \mathrm{~m}^{2}$ foi retirada. Para a determinação da matéria vegetal seca, as amostras foram acondicionadas em sacos de papel e secadas em estufa com circulação forçada de ar a $60 \stackrel{\circ}{ } \mathrm{C}$, até atingir massa constante.

Para determinação dos teores de $\mathrm{Ca}, \mathrm{Mg}$ e $\mathrm{S}$, as amostras foram digeridas em Forno de Micro-ondas Marca CEM, Modelo Mars Xpress, utilizando-se $6 \mathrm{~mL}$ de solução aquosa de ácido nítrico $\left(\mathrm{HNO}_{3}\right)$ 1:1, e 2 $\mathrm{mL}$ de peróxido de hidrogênio $\left(\mathrm{H}_{2} \mathrm{O}_{2}\right)$ a $130 \mathrm{~V}$. Foram utilizados $0,25 \mathrm{~g}$ de tecido vegetal, e o volume foi 
aferido para $30 \mathrm{~mL}$ (diluição de 120x) e a digestão foi realizada em micro-ondas, sob potência de $1600 \mathrm{w}$, e resfriamento por 20 minutos, até temperatura ambiente. Para a análise do $\mathrm{Ca}, \mathrm{Mg}$ e $\mathrm{S}$ foi utilizado o equipamento analítico com espectrômetro de emissão atômica com plasma acoplado indutivamente (ICPOES), marca PerkinElmer, modelo Optima 8300 (Dual View). Este equipamento realiza a leitura das amostras simultaneamente para todos os analitos, e permite ambas as configurações para detecção do sinal (axial e radial).

A quantidade de nutrientes acumulada na palha foi determinada pelo produto da quantidade de massa seca e os teores de nutrientes do resíduo vegetal. A liberação de nutrientes para o solo foi calculada a partir da obtenção desses valores. Utilizando-se a derivada primeira às equações ajustadas aos dados de liberação acumulada dos nutrientes ( $\mathrm{Ca}, \mathrm{Mg}$ e S), foram calculadas as taxas diárias de liberação dos nutrientes após o manejo da fitomassa (ROSOLEM et al. 2003). Foi realizada análise de regressão polinomial para tempo após a dessecação, com auxílio do programa computacional Sistema para Análise de Variância - SISVAR (FERREIRA 2011).

\section{RESULTADOS E DISCUSSÃO}

As condições meteorológicas durante a condução dos experimentos foram apropriadas para o crescimento e desenvolvimento da braquiária (Figura 1). A pastagem de Urochloa brizantha cv. BRS Piatã apresentava no momento inicial da avaliação, para os três piquetes, em torno de $5 \mathrm{t} \mathrm{ha}^{-1}$ de palha (Figura 2). A utilização de pastagens perenes, como a braquiária, fornece significativa quantidade de biomassa, com alta persistência após a dessecação (PACHECO et al. 2008).
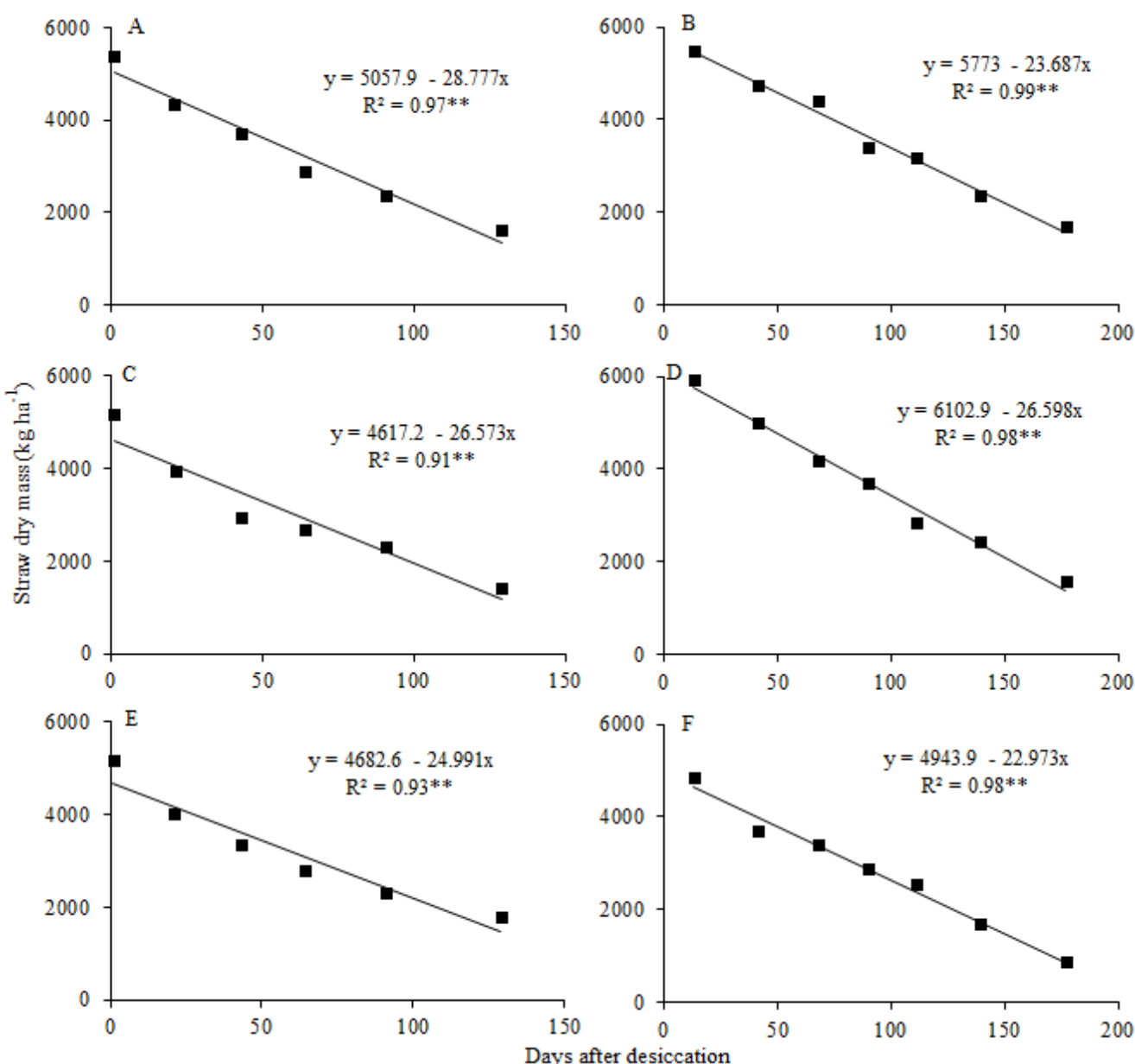

ns, não significativo, ${ }^{* *} \mathrm{e}^{*}$, significativo a $1 \%$ e $5 \%$ de probabilidade, respectivamente, pela análise de regressão.

${ }^{* *}$ and ${ }^{*}$, significant at $1 \%$ and $5 \%$ probability, respectively, by regression analysis.

Figura 2. Massa seca da palha de pastagem de braquiária em três doses de N: 0 (A e B); 150 (C e D) e 300 $\mathrm{kg} \mathrm{N} \mathrm{ha}^{-1}$ (E e F), após a dessecação realizada aos 15 ( $\mathrm{A}, \mathrm{C}$ e E) e 60 (B, D e F) dias antes da semeadura da soja, em função do tempo após a dessecação, Londrina, PR, safra 2017/2018.

Figure 2. Dry matter of straw made from palisade grass fertilized with three different doses of $\mathrm{N}: 0 \mathrm{~kg} \mathrm{~N} \mathrm{ha-1}$ ( $A$ and $B), 150 \mathrm{~kg} \mathrm{~N} \mathrm{ha}^{-1}(C$ and $D)$, and $300 \mathrm{~kg} \mathrm{~N} \mathrm{ha}^{-1}$ ( $E$ and $\left.F\right)$, and then desiccated 15 ( $A, C$, and $E)$ and $60(B, D$, and $F)$ days prior to sowing the soybean crop, expressed as a function of the period of time after desiccation. Londrina, PR, 2017/2018 growing season. 
Os resíduos de braquiária apresentaram um processo de decomposição com padrões similares nos três experimentos, oscilando entre 23 a $29 \mathrm{~kg} \mathrm{ha}^{-1}$ de material vegetal decomposto por dia, apresentando ao final do ciclo da soja cultivada em sucessão cerca de $2 \mathrm{t} \mathrm{ha}^{-1}$. Enfatiza-se que a taxa de decomposição do resíduo é influenciada pela precipitação e pela temperatura ambiente. Deste modo, uma alta variabilidade de resultados pode ser obtida em diferentes condições meteorológicas (CALONEGO et al. 2012, SANTOS et al. 2014). Nas condições da pesquisa, a U. brizantha cv. BRS Piatã proporcionou adequada quantidade de palha para o SPD.

Não houve alterações significativas nos teores de Ca na palha da braquiária ao longo do período de avaliação (Figura 3). Os teores de $\mathrm{Ca}$ na palha foram semelhantes nos três experimentos, ou seja, a adubação nitrogenada na pastagem não influenciou expressivamente os teores desse nutriente na palha oriunda da forragem. BATISTA \& MONTEIRO (2010) observaram que em três cortes da Brachiaria brizantha cultivar Marandu, o teor de Ca na parte aérea apresentou comportamento quadrático para doses de $\mathrm{N}$, em que a aplicação de $\mathrm{N}$ resultou em aumento do teor de $\mathrm{Ca}$ até o ponto em que a resposta foi nula. Por sua vez, COSTA et al. (2008) verificaram que o teor de Ca no capim-xaraés não pastejado não variou em razão das doses de N, em todos os cortes das plantas. Adicionalmente, COSTA et al. (2009) não constataram diferenças significativas no teor de Ca na palha de capim-marandu com a aplicação de $\mathrm{N}$.
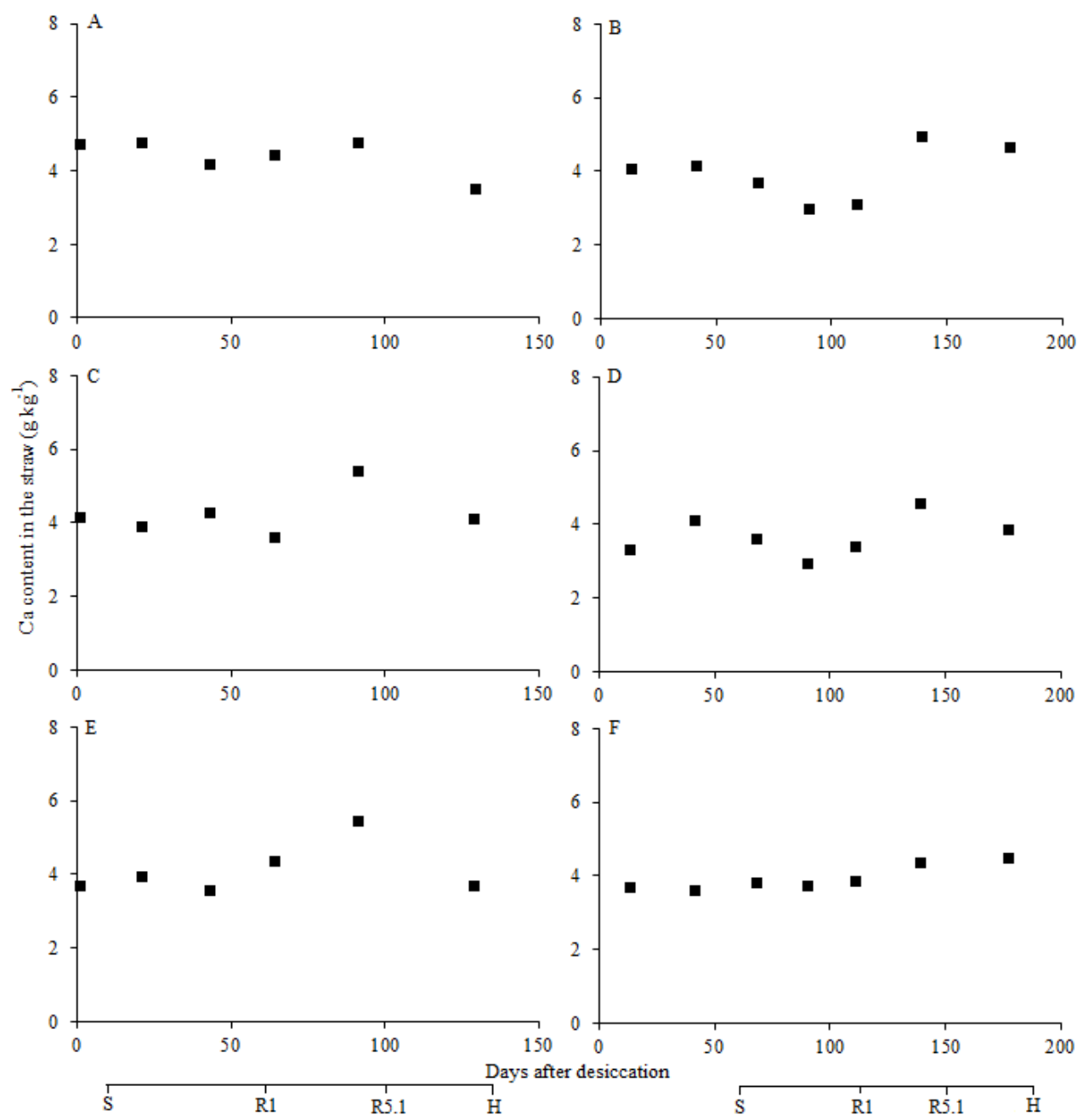

$\mathrm{S}=$ semeadura da soja; $\mathrm{R} 1$ = começo do florescimento da soja; $\mathrm{R} 5.1$ = começo do enchimento de grãos; $\mathrm{H}$ = colheita da soja.

$S=$ soybean sowing; $R 1=$ beginning of soybean flowering; $R 5.1$ = beginning of grain filling; $H=$ soybean harvest.

Figura 3. Teor de Cálcio ( $\mathrm{Ca})$ na palha de pastagem de braquiária em três doses de N: 0 ( $A$ e B); 150 (C e D) e $300 \mathrm{~kg} \mathrm{~N} \mathrm{ha}^{-1}$ (E e F), após a dessecação realizada aos 15 ( $A, C$ e E) e 60 (B, D e F) dias antes da semeadura da soja, em função do tempo após a dessecação, Londrina, PR, safra 2017/2018.

Figure 3. Calcium (Ca) content in straw made from palisade grass fertilized with three different doses of $\mathrm{N}: 0$ $\mathrm{kg} \mathrm{N} \mathrm{ha}^{-1}(A$ and $B), 150 \mathrm{~kg} \mathrm{Nha}^{-1}(C$ and $D)$, and $300 \mathrm{~kg} \mathrm{Nha}^{-1}(E$ and $F)$, and then desiccated 15 $(A, C$, and $E)$ and $60(B, D$, and $F)$ days prior to sowing the soybean crop, expressed as a function of the period of time after desiccation. Londrina, PR, 2017/2018 growing season. 
A dinâmica de liberação de $\mathrm{Ca}$ da palha para o solo foi similar nas três doses de $\mathrm{N}$ na pastagem e nas duas épocas de dessecação da pastagem (Figura 4). Ao final do período de avaliação, a palha da pastagem de braquiária liberou cerca de $15 \mathrm{~kg} \mathrm{ha}^{-1}$ de Ca. PRIMAVESI et al. (2006) constataram que o aumento das doses de $\mathrm{N}$ proporcionou redução dos teores de $\mathrm{Ca}$ em capim-marandu, entretanto os autores ressaltam que a forma em que o $\mathrm{N}$ se encontra no solo pode influenciar na absorção do $\mathrm{Ca}$. $\mathrm{O}$ tempo para a liberação de $50 \%$ do Ca foi de 75 a 95 dias para a braquiária dessecada 15 dias antes da semeadura da soja e em torno de 130 dias para a dessecação 60 dias antes da semeadura da soja, considerada uma liberação lenta, o que favorece o aproveitamento desse nutriente pela cultura da soja. Isso pode ser explicado em razão de que o Ca não é um nutriente de fácil remoção, sendo o principal componente da parede celular (CAVALLI et al. 2018).
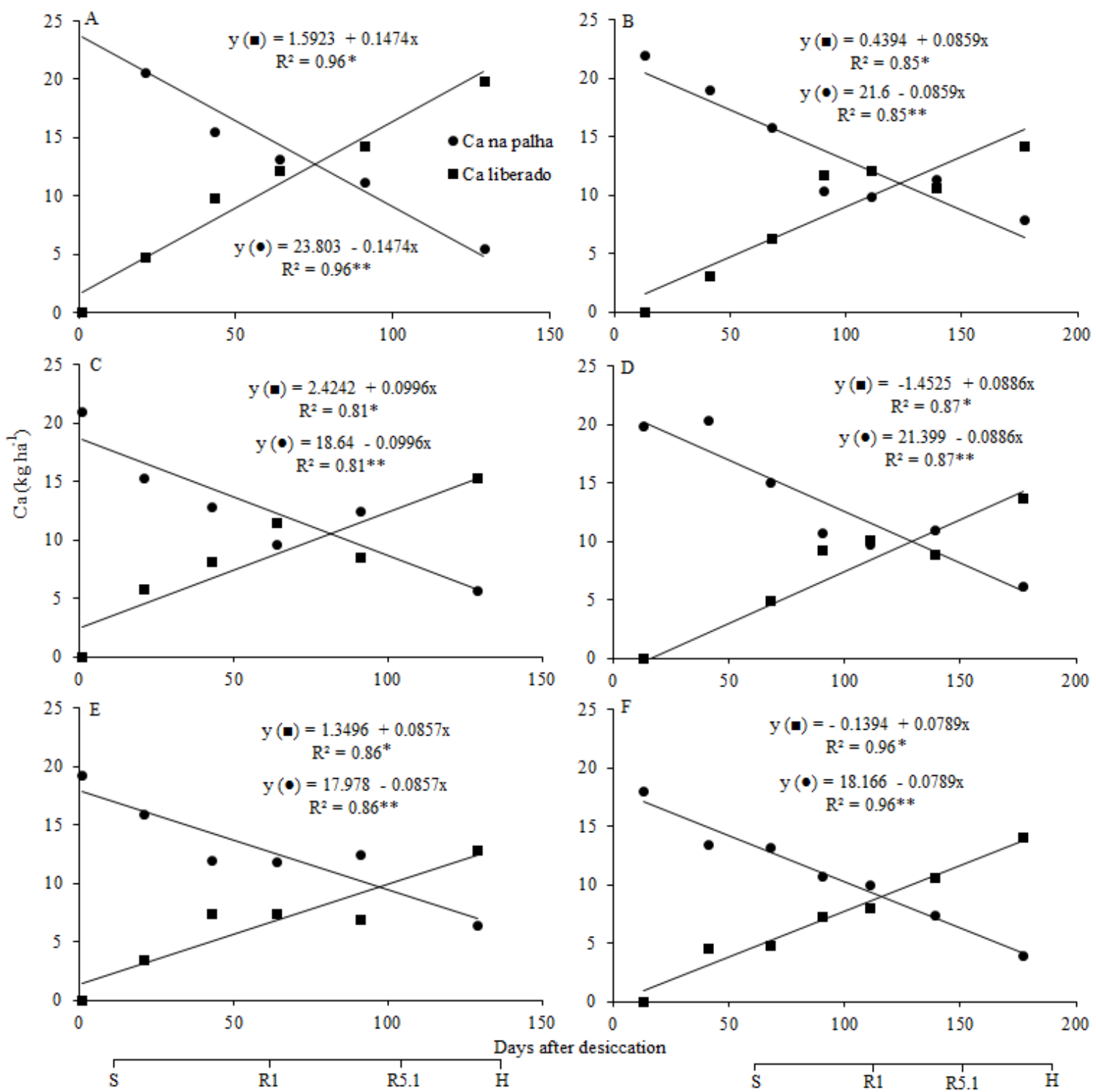

${ }^{* *}$ e *, significativo a $1 \%$ e $5 \%$ de probabilidade, respectivamente, pela análise de regressão. $S=$ semeadura da soja; R1: começo do florescimento da soja; R5.1 = começo do enchimento de grãos; $\mathrm{H}=$ colheita da soja.

${ }^{* *}$ and *, significant at $1 \%$ and $5 \%$ probability, respectively, by regression analysis. $\mathrm{S}=$ soybean sowing; R1: beginning of soybean flowering; $\mathrm{R} 5.1$ = beginning of grain filling; $\mathrm{H}$ = soybean harvest.

Figura 4. Quantidade de cálcio na palha de pastagem de braquiária $(\bullet)$ e liberação acumulada $(\square)$ em três doses de N: 0 (A e B); 150 (C e D) e $300 \mathrm{~kg} \mathrm{~N} \mathrm{ha}^{-1}$ (E e F), após a dessecação realizada aos 15 $(A, C$ e E) e 60 (B, D e F) dias antes da semeadura da soja, em função do tempo após a dessecação, Londrina, PR, safra 2017/2018.

Figure 4. Amount of Calcium in the straw ( $\bullet$ ) and the cumulative amount of $N$ released from straw ( $\boldsymbol{\nabla})$ made from palisade grass fertilized with three different doses of $\mathrm{N}: 0 \mathrm{~kg} \mathrm{~N} \mathrm{ha}{ }^{-1}\left(A\right.$ and $B$ ), $150 \mathrm{~kg} \mathrm{~N} \mathrm{ha}{ }^{-1}$ $(C$ and $D)$, and $300 \mathrm{~kg} \mathrm{Nha}^{-1}(E$ and $F)$, and then desiccated $15(A, C$, and $E)$ and 60 (B, D, and $F$ ) days prior to sowing the soybean crop, expressed as a function of the period of time after desiccation. Londrina, PR, 2017/2018 growing season. 
Resultados contrastantes foram obtidos por MENDONÇA et al. (2015), que observaram rápida liberação de $\mathrm{Ca}$, em até 10 dias após o manejo, com redução constante a partir de 20 dias e apresentando tendência à estabilização em valores aproximados a zero para a U. brizantha cv. Marandu e U. ruziziensis. CAVALLI et al. (2018) em estudo com três resíduos (milho, consórcio milho-braquiária e braquiária) para o cultivo da soja em sucessão, observaram que a braquiária demorou 62 dias para liberar metade do $\mathrm{Ca}$ presente na palha

Houve tendência de redução dos teores de $\mathrm{Mg}$ ao longo do período de avaliação da decomposição da palha nas três doses de $\mathrm{N}$ e nas duas épocas de dessecação na pastagem de braquiária (Figura 5). A concentração de $\mathrm{Mg}$ apresenta redução com o passar do tempo, pois a maior parte do $\mathrm{Mg}$ não faz parte de componentes celulares e estruturais das plantas (CRUSCIOL et al. 2008). A dinâmica de liberação de Mg da palha para o solo foi similar para os três experimentos e as duas épocas de dessecação (Figura 6). Até o final do ciclo da soja cultivada em sucessão, a quantidade liberada pela palha variou de 10 e $15 \mathrm{~kg} \mathrm{ha}^{-1} \mathrm{de}$ Mg.
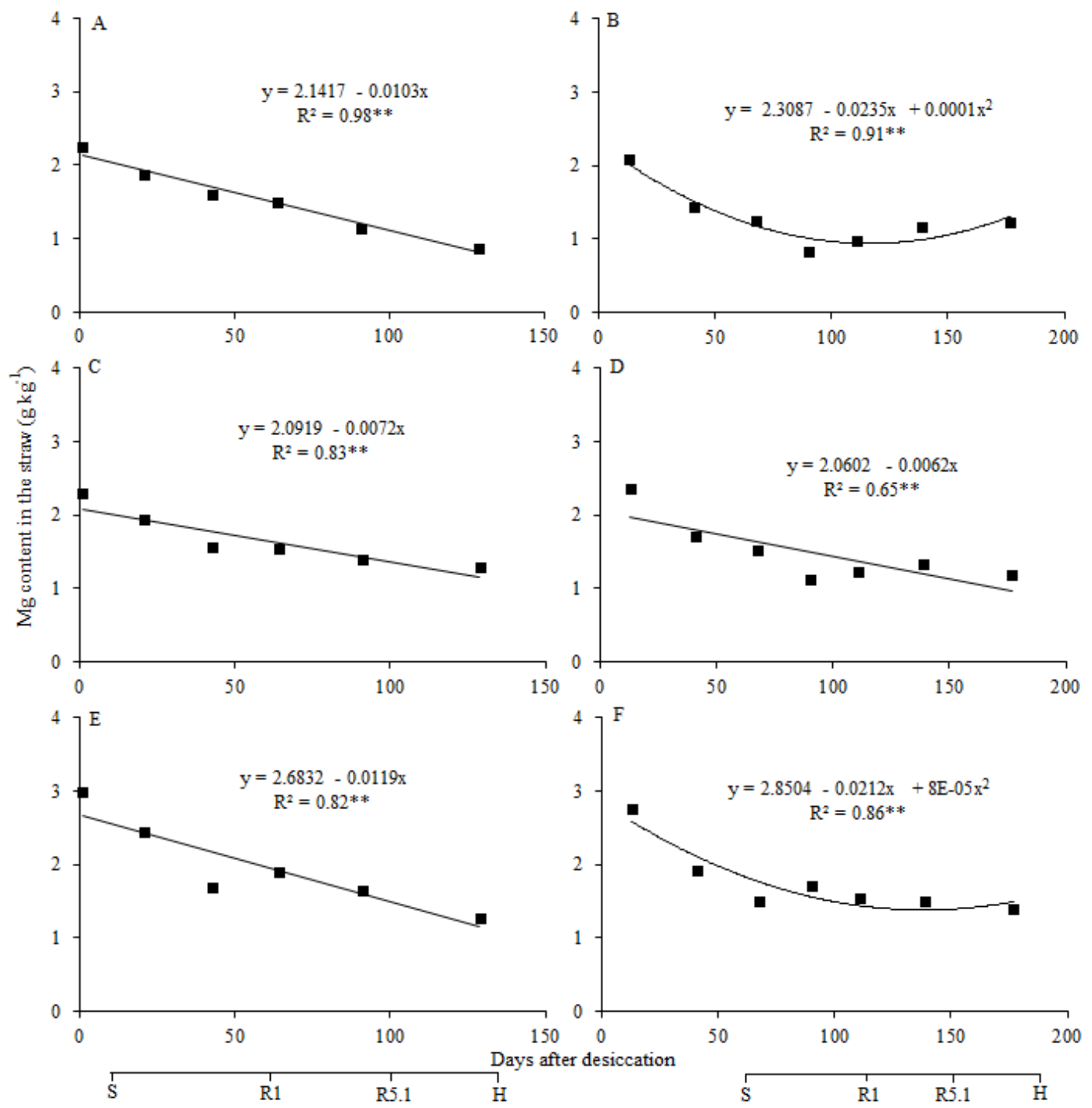

** e *, significativo a $1 \%$ e $5 \%$ de probabilidade, respectivamente, pela análise de regressão. $\mathrm{S}=$ semeadura da soja; R1: começo do florescimento da soja; R5.1 = começo do enchimento de grãos; $\mathrm{H}=$ colheita da soja.

${ }^{* *}$ and ${ }^{*}$, significant at $1 \%$ and $5 \%$ probability, respectively, by regression analysis. $\mathrm{S}=$ soybean sowing; R1: beginning of soybean flowering; $\mathrm{R} 5.1$ = beginning of grain filling; $\mathrm{H}=$ soybean harvest.

Figura 5. Teor de Magnésio (Mg) na palha de pastagem de braquiária em três doses de N: 0 (A e B); 150 (C e D) e $300 \mathrm{~kg} \mathrm{~N}^{-1}$ (E e F), após a dessecação realizada aos 15 (A, C e E) e 60 (B, D e F) dias antes da semeadura da soja, em função do tempo após a dessecação, Londrina, PR, safra 2017/2018.

Figure 5. Magnesium (Mg) content in straw made from palisade grass fertilized with three different doses of $\mathrm{N}$ : $0 \mathrm{~kg} \mathrm{~N} \mathrm{ha}{ }^{-1}(A$ and $B), 150 \mathrm{~kg} \mathrm{Nha}^{-1}(C$ and $D)$, and $300 \mathrm{~kg} \mathrm{~N} \mathrm{ha}^{-1}$ ( $E$ and $F$ ), and then desiccated $15(A, C$, and $E)$ and $60(B, D$, and $F)$ days prior to sowing the soybean crop, expressed as a function of the period of time after desiccation. Londrina, PR, 2017/2018 growing season. 

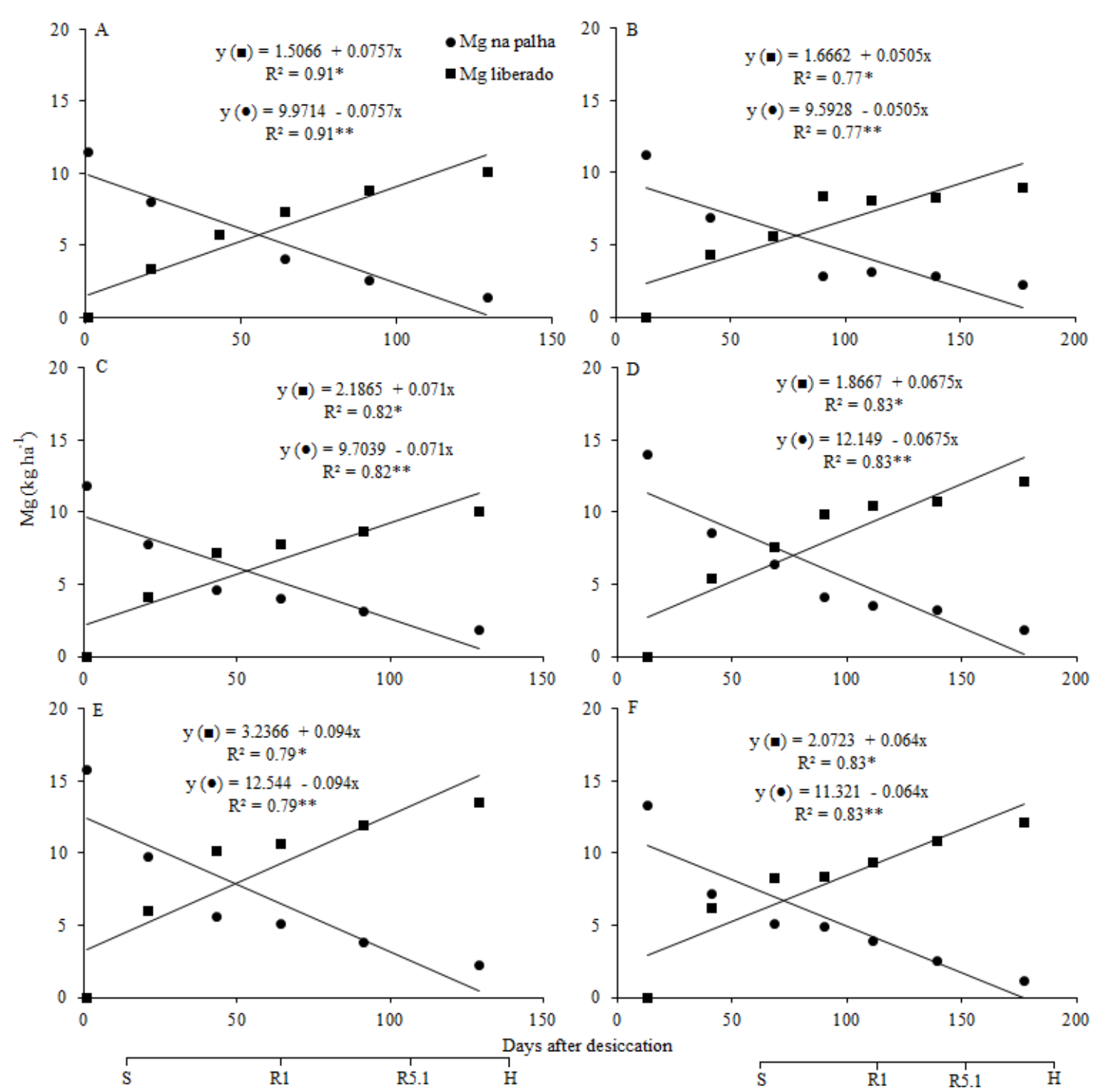

ns, ${ }^{* *} e^{*}$, significativo a $1 \%$ e $5 \%$ de probabilidade, respectivamente, pela análise de regressão. S = semeadura da soja; R1: começo do florescimento da soja; $\mathrm{R} 5.1$ = começo do enchimento de grãos; $\mathrm{H}=$ colheita da soja.

${ }^{* *}$ and *, significant at $1 \%$ and $5 \%$ probability, respectively, by regression analysis. $\mathrm{S}=$ soybean sowing; R1: beginning of soybean flowering; $\mathrm{R} 5.1$ = beginning of grain filling; $\mathrm{H}$ = soybean harvest.

Figura 6. Quantidade de magnésio na palha de pastagem de braquiária $(\bullet)$ e liberação acumulada $(\square)$ em três doses de N: 0 ( $A$ e B); 150 (C e D) e $300 \mathrm{~kg} \mathrm{~N}$ ha $^{-1}$ (E e F), após a dessecação realizada aos 15 ( $A, C$ e E) e 60 (B, D e F) dias antes da semeadura da soja, em função do tempo após a dessecação, Londrina, PR, safra 2017/2018.

Figure 6. Amount of Magnesium in the straw ( $\bullet$ ) and the cumulative amount of $N$ released from straw ( $\boldsymbol{\square})$ made from palisade grass fertilized with three different doses of $\mathrm{N}: 0 \mathrm{~kg} \mathrm{~N} \mathrm{ha}{ }^{-1}(A$ and $B), 150 \mathrm{~kg} \mathrm{~N}$ $\mathrm{ha}^{-1}(C$ and $D)$ and $300 \mathrm{~kg} \mathrm{Nha}^{-1}(E$ and $F)$, and then desiccated $15(A, C$, and $E)$ and $60(B, D$, and $F$ ) days prior to sowing the soybean crop, expressed as a function of the period of time after desiccation. Londrina, PR, 2017/2018 growing season.

O tempo necessário para liberar $50 \%$ de $\mathrm{Mg}$ foi em torno de 50 e 75 dias para a dessecação realizada 15 e 60 dias antes da semeadura da soja, respectivamente. Corroborando os dados da presente pesquisa, SANTOS et al. (2014) observaram que a B. ruziziensis demorou 68 dias para liberar $50 \%$ de $\mathrm{Mg}$. Por outro lado, TORRES et al. (2008) constataram que a palha de B. brizantha, utilizada como planta de cobertura, levou 11 dias para liberar metade do $\mathrm{Mg}$, valores bem inferiores aos obtidos neste estudo. CAVALLI et al. (2018) observaram que a braquiária liberou metade do $\mathrm{Mg}$ da palha em apenas 35 dias. As variações observadas no tempo para liberação do $\mathrm{Mg}$ podem ser decorrentes, principalmente, de variações genéticas, idade das plantas, relação folha/colmo, teores de outros nutrientes na biomassa e condições climáticas, sobretudo temperatura e precipitação.

O teor de $S$ na palha da pastagem de braquiária não variou durante o período de avaliação da 
decomposição, para os três experimentos e nas duas épocas de dessecação (Figura 7). Também não houve variações expressivas no teor desse nutriente entre as três doses de $\mathrm{N}$. Resultados contrastantes foram obtidos por COSTA et al. (2009) que observaram que as doses $\left(0,100,200\right.$ e $\left.300 \mathrm{~kg} \mathrm{ha}^{-1} \mathrm{ano}^{-1}\right)$ e fontes de $\mathrm{N}$ (sulfato de amônio e ureia) influenciaram na concentração desse nutriente no capim-marandu, constatando aumento linear na concentração de $\mathrm{S}$ em ambas as fontes, em função das doses de $\mathrm{N}$. Entretanto, PRIMAVESI et al. (2006) observaram que o incremento de doses de ureia $(0,50,100$ e $200 \mathrm{~kg}$ ha $^{-1}$ corte $\left.^{-1}\right)$ não proporcionou diferenças nas concentrações de $\mathrm{S}$ em capim-marandu, obtendo valores em torno de $1,4 \mathrm{~g} \mathrm{~kg}^{-1}$ desse nutriente.
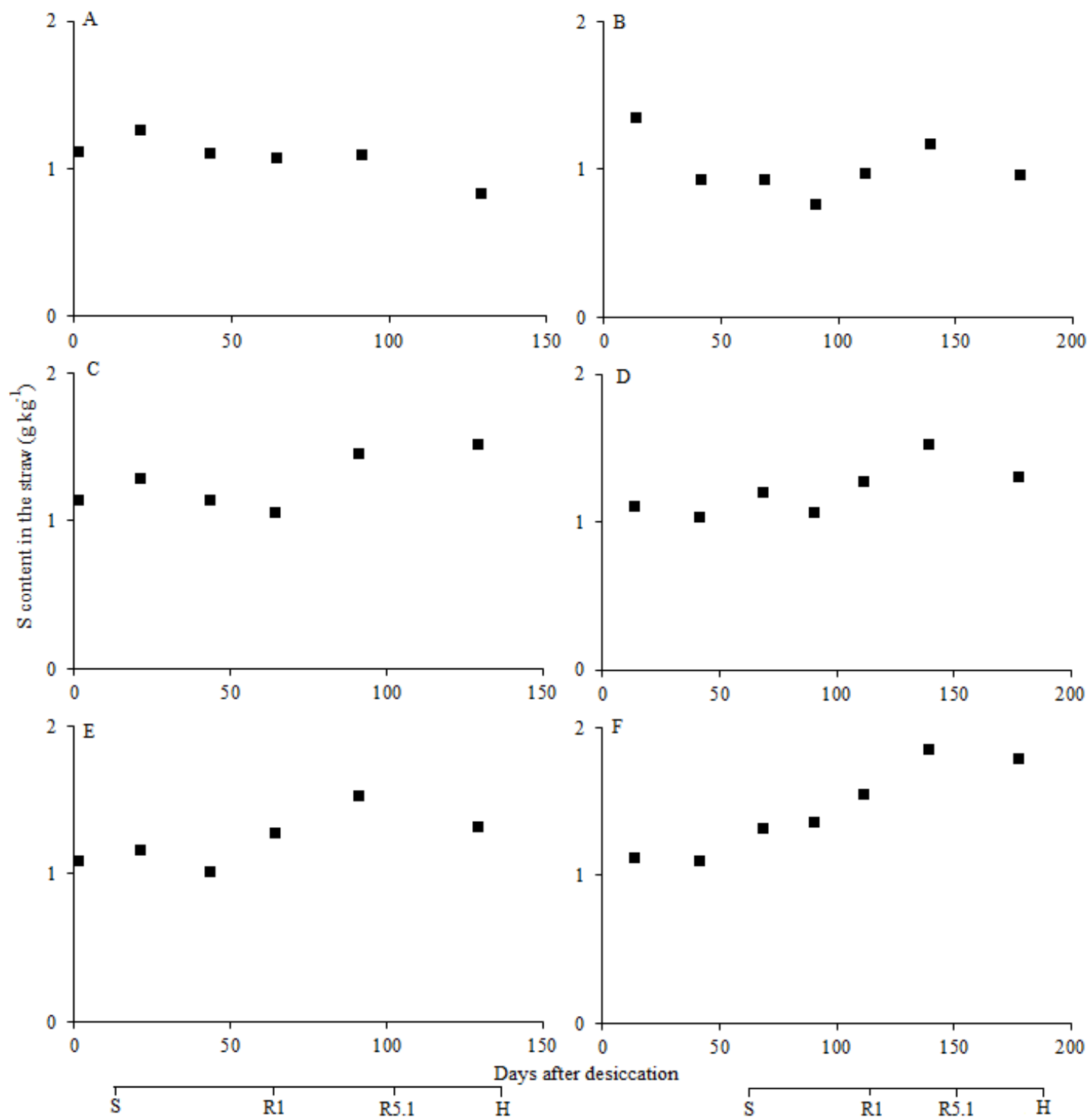

$\mathrm{S}=$ semeadura da soja; $\mathrm{R} 1$ = começo do florescimento da soja; $\mathrm{R} 5.1$ = começo do enchimento de grãos; $\mathrm{H}=$ colheita da soja.

$\mathrm{S}$ = soybean sowing; $\mathrm{R} 1$ = beginning of soybean flowering; $\mathrm{R} 5.1$ = beginning of grain filling; $\mathrm{H}=$ soybean harvest.

Figura 7. Teor de Enxofre (S) na palha de pastagem de braquiária em três doses de N: 0 ( $A$ e B); 150 ( $C$ e D) e $300 \mathrm{~kg} \mathrm{~N} \mathrm{ha}^{-1}$ (E e F), após a dessecação realizada aos 15 (A, C e E) e 60 (B, D e F) dias antes da semeadura da soja, em função do tempo após a dessecação, Londrina, PR, safra 2017/2018.

Figure 7. Sulfur (S) content in straw made from palisade grass fertilized with three different doses of $\mathrm{N}: 0 \mathrm{~kg}$ $N \mathrm{ha}^{-1}(A$ and $B), 150 \mathrm{~kg} \mathrm{Nha}^{-1}(C$ and $D)$ and $300 \mathrm{~kg} \mathrm{Nha}^{-1}$ ( $E$ and $\left.F\right)$, and then desiccated 15 ( $A$, $C$, and $E)$ and $60(B, D$, and $F)$ days prior to sowing the soybean crop, expressed as a function of the period of time after desiccation. Londrina, PR, 2017/2018 growing season.

Verificou-se que para a dessecação realizada 60 dias antes da semeadura da soja, a palha oriunda da pastagem conduzida sem adição de $\mathrm{N}$ liberou cerca de $6 \mathrm{~kg} \mathrm{ha}^{-1}$ de $\mathrm{S}$ até o final do ciclo da soja (Figura $8 \mathrm{~B}$ ). No entanto, as palhas das pastagens adubadas com $\mathrm{N}$ liberaram cerca de $4 \mathrm{~kg} \mathrm{ha}^{-1}$ de $\mathrm{S}$ (Figuras 8D e 
F). Esse comportamento também foi observado para a liberação de $S$ na dessecação realizada 15 dias antes da semeadura da soja (Figuras 8A, C e E).
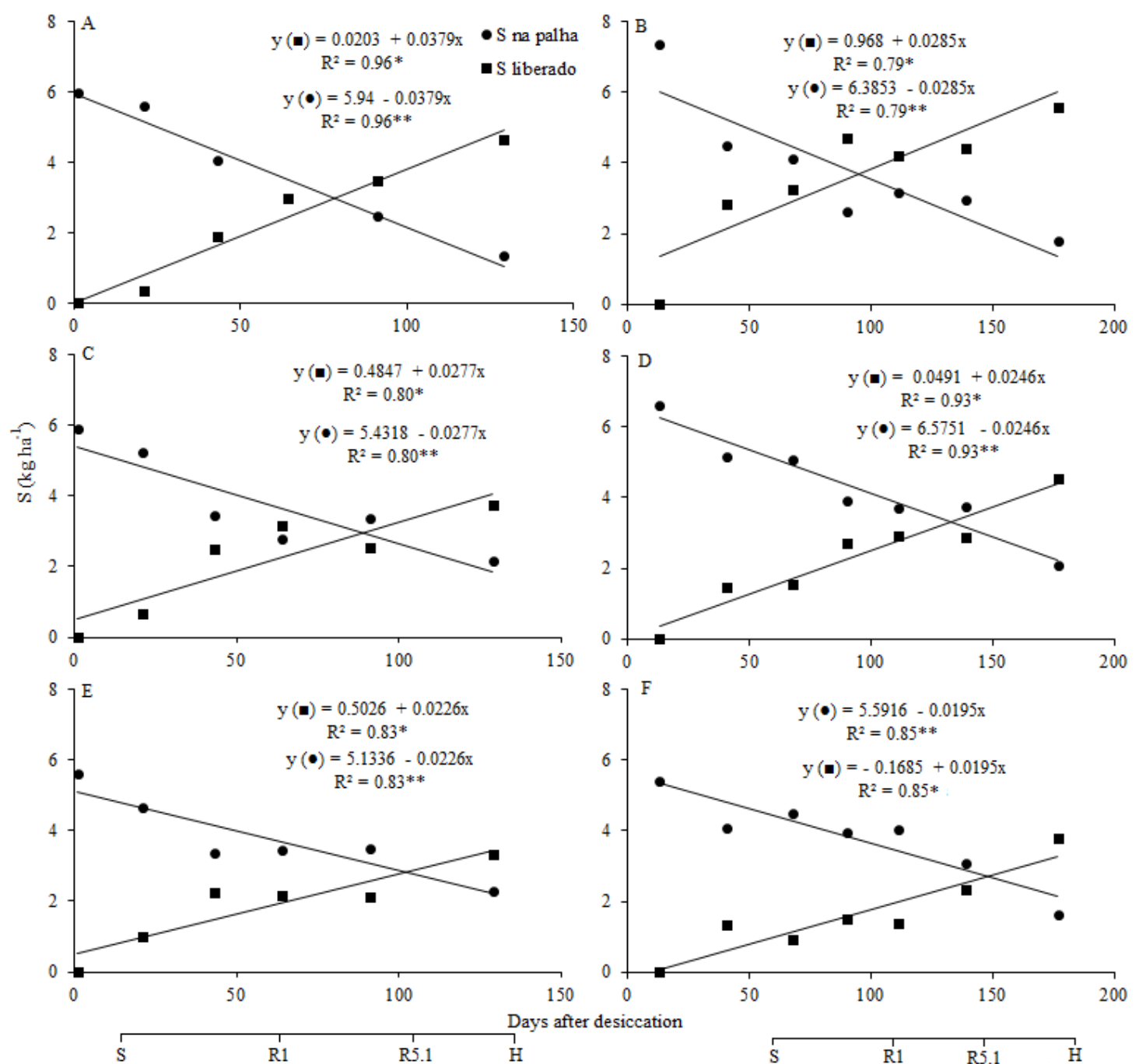

${ }^{* *}$ e *, significativo a $1 \%$ e $5 \%$ de probabilidade, respectivamente, pela análise de regressão. $\mathrm{S}=$ semeadura da soja; R1: começo do florescimento da soja; R5.1 = começo do enchimento de grãos; $\mathrm{H}$ = colheita da soja.

${ }^{* *}$ and *, significant at $1 \%$ and $5 \%$ probability, respectively, by regression analysis. $\mathrm{S}=$ soybean sowing; $\mathrm{R} 1$ : beginning of soybean flowering; $\mathrm{R} 5.1$ = beginning of grain filling; $\mathrm{H}$ = soybean harvest.

Figura 8. Quantidade de enxofre na palha de pastagem de braquiária $(\bullet)$ e liberação acumulada $(\square)$ em três doses de N: 0 ( $A$ e B); 150 (C e D) e $300 \mathrm{~kg} \mathrm{~N}$ ha $^{-1}$ (E e F), após a dessecação realizada aos 15 ( $A, C$ e E) e 60 (B, D e F) dias antes da semeadura da soja, em função do tempo após a dessecação, Londrina, PR, safra 2017/2018.

Figure 8. Amount of Sulfur in the straw ( $\bullet$ ) and the cumulative amount of $N$ released from straw ( $\square$ ) made from palisade grass fertilized with three different doses of $\mathrm{N}: 0 \mathrm{~kg} \mathrm{~N} \mathrm{ha}{ }^{-1}(A$ and $B), 150 \mathrm{~kg} \mathrm{~N} \mathrm{ha}^{-1}$ $(C$ and $D)$, and $300 \mathrm{~kg} \mathrm{Nha}^{-1}(E$ and $F)$, and then desiccated $15(A, C$, and $E)$ and 60 (B, D, and $F$ ) days prior to sowing the soybean crop, expressed as a function of the period of time after desiccation. Londrina, PR, 2017/2018 growing season.

A maior parte do S é ciclado biogeoquimicamente, sendo que para essa ciclagem acontecer depende da deposição de resíduos vegetais sobre o solo e consequentemente a mineralização por microrganismos. Dentro das células vegetais, o $\mathrm{S}$ é armazenado nos vacúolos ou pode ser rapidamente incorporado em compostos orgânicos (GOTOR et al. 2015). Cerca de $90 \%$ do $S$ encontrado na planta faz parte da constituição de aminoácidos: cistina, cisteína e metionina. O S está ligado diretamente ao metabolismo do $\mathrm{N}$, sendo necessário para a formação de qualquer proteína que apresente na sua constituição esses aminoácidos (ANJUM et al. 2015). Provavelmente, com a aplicação de N houve imobilização temporária do $S$ na palhada produzida, demorando mais tempo para liberá-lo.

A liberação de $S$ foi lenta durante o período avaliado, sendo que o tempo necessário para liberar $50 \%$ do nutriente foi cerca de 90 e 135 dias para a dessecação realizada aos 15 e 60 dias antes da semeadura 
da soja, respectivamente. SANTOS et al. (2014) observaram em B. ruziziensis que o $S$ teve liberação de 7,7 $\mathrm{kg} \mathrm{ha}^{-1}$ e levou 78 dias para liberar metade dessa quantidade. Entretanto, TORRES et al. (2008) constataram que o $S$ demorou 18 dias para liberar $50 \%$ de $S$ em B. brizantha cv Marandu.

De forma geral, na presente pesquisa, as quantidades de nutrientes liberadas pela palha tiveram a seguinte ordem $\mathrm{Ca}>\mathrm{Mg}>\mathrm{S}$, independentemente da aplicação de $\mathrm{N}$ na pastagem ou época de dessecação. As quantidades de $\mathrm{Ca}, \mathrm{Mg}$ e $\mathrm{S}$ liberadas pela palha de $U$. brizantha conseguem suprir a exportação de cinco toneladas de grãos de soja, em 100\% para os nutrientes Ca e Mg e em 18,5\% para o S, levando em consideração a inexistência de perdas no sistema, como erosão ou lixiviação, já que para produzir uma tonelada de grãos de soja são exportados em torno de $3,0 \mathrm{~kg}$ de $\mathrm{Ca}, 2,0 \mathrm{~kg}$ de $\mathrm{Mg}$ e de $5,4 \mathrm{~kg}$ de $\mathrm{S}$ (EMBRAPA 2013). Em função da reduzida velocidade de liberação de $\mathrm{Ca}, \mathrm{Mg}$ e $\mathrm{S}$ da palha de pastagem de $U$. brizantha cv. BRS Piatã, as dessecações antecipadas não interfeririam no aproveitamento dos nutrientes pela soja em sucessão.

\section{CONCLUSÃO}

Os teores de Ca e S na palha de pastagem de U. brizantha não variam com o tempo de decomposição, enquanto os teores de magnésio reduzem, independentemente da adubação nitrogenada e da época de dessecação.

A quantidade de Ca liberada pela palha de pastagem de U. brizantha, até o final do ciclo da soja em sucessão, foi de, aproximadamente, $15 \mathrm{~kg} \mathrm{ha}^{-1}$, independentemente da adubação nitrogenada e da época de dessecação.

A quantidade de $\mathrm{Mg}$ liberada pela palha de pastagem de $U$. brizantha, até o final do ciclo da soja em sucessão, variou de 10 a $15 \mathrm{~kg} \mathrm{ha}^{-1}$, com tendência de haver maior quantidade liberada na presença de adubação nitrogenada na pastagem.

A quantidade de $S$ liberado pela palha de pastagem de $U$. brizantha, até o final do ciclo da soja em sucessão, variou de 4 a $6 \mathrm{~kg} \mathrm{ha}^{-1}$, com tendência de haver menor quantidade liberada na presença de adubação nitrogenada na pastagem, independentemente da época de dessecação.

\section{REFERÊNCIAS}

ANJUM NA et al. 2015. ATP-sulfurylase, sulfur-compounds, and plant stress tolerance. Frontiers in Plant Science 6: 1-9.

BALBINOT JUNIOR AA et al. 2009. Integração lavoura-pecuária: intensificação de uso de áreas agrícolas. Ciência Rural 39: 1925-1933.

BATISTA K \& MONTEIRO FA. 2010. Variações nos teores de potássio, cálcio e magnésio em capim-marandu adubado com doses de nitrogênio e de enxofre. Revista Brasileira de Ciência do Solo 34: 151-161.

CALONEGO JC et al. 2012. Persistência e liberação de nutrientes da palha de milho, braquiária e labe-labe. Bioscience Journal 28: 770-781.

CAVALLI E et al. 2018. Decomposition and release of nutrients from crop residues on soybean-maize cropping systems. Revista Brasileira de Ciências Agrárias 13: 1-8.

COSTA KAP et al. 2008. Adubação nitrogenada e potássica na concentração de nutrientes do capim-xaraés. Ciência Animal Brasileira 9: 86-92.

COSTA KAP et al. 2009. Doses e fontes de nitrogênio na nutrição mineral do capim-marandu. Ciência Animal Brasileira 10: $115-123$.

COSTA CHM et al. 2016. Nitrogen fertilization on palisadegrass: phytomass decomposition and nutrients release. Pesquisa Agropecuária Tropical 46: 159-168.

CRUSCIOL CAC et al. 2008. Taxas de decomposição e de liberação de macronutrientes da palhada de aveia preta em plantio direto. Bragantia 67: 481-489.

DUPAS E et al. 2016. Nitrogen recovery, use efficiency, dry matter yield, and chemical composition of palisade grass fertilized with nitrogen sources in the Cerrado biome. Australian Journal of Crop Science 10: 1330-1338.

ECHER FR et al. 2012. Crescimento inicial e absorção de nutrientes pelo algodoeiro cultivado sobre a palhada de Brachiaria ruziziensis. Planta Daninha 30: 783-790.

EMBRAPA. 2013. Empresa Brasileira de Pesquisa Agropecuária. Sistemas de produção 16: Tecnologias de Produção de Soja - Região Central do Brasil 2014. Londrina Embrapa Soja. 266p.

FERREIRA DF. 2011. Sisvar: A computer statistical analysis system. Ciência e Agrotecnologia 35: 1039-1042.

FRANCHINI JC et al. 2014. Soybean performance as affected by desiccation time of Urochloa ruziziensis and grazing pressures. Revista Ciência Agronômica 45: 999-1005.

FRANCHINI JC et al. 2015. Desempenho da soja em consequência de manejo de pastagem, época de dessecação e adubação nitrogenada. Pesquisa Agropecuária Brasileira 50: 1131-1138.

GOTOR C et al. 2015. Signaling in the plant cytosol: cysteine or sulfide? Amino Acids 47: 2155-2164.

KUMAR SV et al. 2019. Facilitating crop-livestock reintegration in the Northern Great Plains. Agronomy Journal 111: 2141-2156. 
MENDONÇA VZ et al. 2015. Liberação de nutrientes da palhada de forrageiras consorciadas com milho e sucessão com soja. Revista Brasileira de Ciência do Solo 39: 183-193.

MONQUERO PA et al. 2010. Intervalo de dessecação de espécies de cobertura do solo antecedendo a semeadura da soja. Planta Daninha 28: 561-573.

NASCENTE AS \& CRUSCIOL CAC. 2012. Cover crops and herbicide timing management on soybean yield under notillage system. Pesquisa Agropecuária Brasileira 47: 187-192.

NEPOMUCENO MP et al. 2012. Períodos de dessecação de Urochloa ruziziensis e seu reflexo na produtividade da soja RR. Planta Daninha 30: 557-565.

PACHECO LP et al. 2008. Desempenho de plantas de cobertura em sobressemeadura na cultura da soja. Pesquisa Agropecuária Brasileira 43: 815-823.

PRIMAVESI AC et al. 2006. Nutrientes na fitomassa de capim marandu em função de fontes e doses de nitrogênio. Ciência e Agrotecnologia 30: 562-568.

ROSOLEM CA et al. 2003. Lixiviação de potássio da palhada de espécies de cobertura de solo de acordo com a quantidade de chuva aplicada. Revista Brasileira de Ciência do Solo 27: 355-362.

SANTOS FC et al. 2014. Decomposição e liberação de macronutrientes da palhada de milho e braquiária, sob integração lavoura-pecuária no cerrado baiano. Revista Brasileira de Ciência do Solo 38: 1855-1861.

SANTOS HG et al. 2018. Sistema Brasileiro de Classificação de Solos. 5.ed. Brasília: EMBRAPA. 355p.

TORRES JLR et al. 2008. Produção de fitomassa por plantas de cobertura e mineralização de seus resíduos em plantio direto. Pesquisa Agropecuária Brasileira 43: 421-428. 